\title{
AUTOMATED MATERIAL HANDLING USING RFID
}

\author{
Smitha $\mathbf{M}^{1}$, Vinod Kumar M S ${ }^{2}$, R Suresh ${ }^{3}$ \\ ${ }^{I}$ Student, Department of Industrial Automation Engineering VTU PG Center Mysore, India \\ smithu.mm@gmail.com \\ ${ }^{2}$ Assistant Professor, Department of Industrial Automation Engineering VTU PG Centre Mysore, India \\ vinod.sadashiv@gmail.com \\ ${ }^{3}$ Professor, Department of Industrial Automation Engineering VTU PG Centre Mysore, India \\ drsureshvtu@gmail.com
}

\begin{abstract}
In this project automated guided vehicle $(A G V)$ is controlled using RFID. The vehicle moves from source to destination when the RFID tag is read. There are sensors present on the vehicle for obstacle avoidance and overload detection. The GSM module is used to get SMS to help the operator at the control station.
\end{abstract}

Keywords: RFID (Radio frequency identification), GSM (Global system for mobile communication), AGV (Automated guided vehicle).

\section{INTRODUCTION}

An automated system is one in which a process is performed by a machine without the direct participation of a human worker. Automation is implemented using a program of instructions combined with a control system that executes the instructions. Robots are being used in a wide field of applications in industry. In material handling applications, the robots moves materials or parts from one place to another. An AGV is a material handling system that uses independently operated, self-propelled vehicles guided along defined pathways. AGV has firstly developed and conducted the research and an attempt to use at the Jumbo Truck Manufacturing in Thailand. AGV systems are used in a growing number and variety of applications. Next generation material handling should be highly automated and based on next generation technologies, and should very flexible and able to respond to the manufacturing system.

This project illustrates the control of such AGVs using one of the most advantageous wireless technologies available in recent times that is the RFID (Radio Frequency Identification Technology). In radio frequency identification “

is attached. This tag contains up to 20 alpha numeric characters for identifying the product to which the tag is attached.

\section{LITRATURE SURVEY}

A. An RFID based pilgrim identification system-

\section{Mohammed Mohandes, MaanKousa, Ahmed A}

\section{Hussain.}

In this paper RFID is used as an effective, convenient and economical solution to the Hajj problem. A wristband RFID tag that can be worn at all times can be provided to each pilgrim. This tag when presented to an RFID reader theinformation stored in the tag can be retrieved and displayed on a handheld portable unit.

B. control and path prediction of an Automated guided vehicle-S.Butdee, A.Suebsomran, F.Vignat, P.K.D.V.Yarlagadda.

In this paper a new architecture and control strategy of the $\mathrm{AGV}$ is proposed. It is a three wheels vehicle. The front wheel is used for driving and steering the AGV and the two rare wheels are free. The steering and driving are DC motor. A Programmable Logic Control (PLC) is used for motion control.

\section{Estimation and control of an automated guided}

vehicle-Suthep Butdee, Frederic Vignat, Anan

\section{Suebsomran, Prasad KDV Yarlagadda.}

In this paper a control strategy of Automated Guided Vehicle is proposed. The vehicle movement controlled by an inboard PLC do not need physical guide. The vehicle has 3 wheels. The strategy is based on 2 main purposes: the path is stored in the PLC memory and the vehicle displacement is calculated from the wheel rotation measurement. 


\section{BLOCK DIAGRAM}

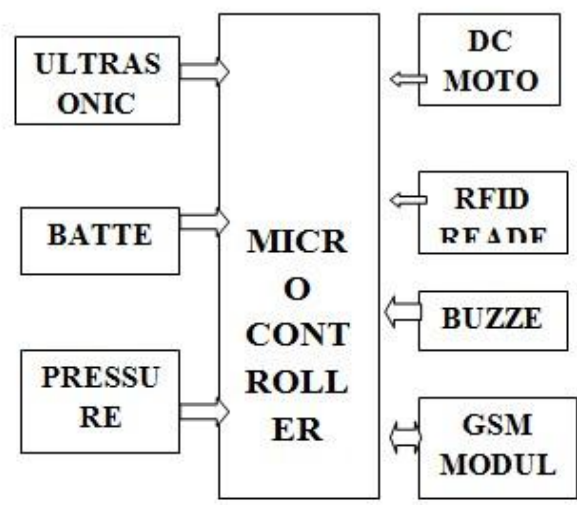

Fig1: Block diagram

Movement of vehicle: The movement the vehicle is done with the help of DC motor and it is controlled RFID. When arespective RFID tag is read at the start point the vehicle moves in the predefined path to the destination.

Micro controller: All the modules are connected to the micro controller and the micro controller gives command to the modules with respect to their application.

Ultrasonic sensor: The main purpose of this sensor is to detect an obstacle in the pathway of the vehicle. This will give a buzzer and an SMS indication to the operator.

GSM module: Global system for mobile communication is used to get SMS or message alters about the various operation of the vehicle like obstacle detection, overloading.

Pressure sensor: This is used to detect whether the AGV is over loaded. If in case over loading has occurred it give SMS alter and a buzzer to indicate to the operator.

\section{OPERATION}

At the beginning the goods are loaded into the AGV the system checks for any overload if yes it sends a SMS alert to the operating station. If not, when the RFID tag is read the AGV starts to move from source to destination in the predefined path. If any obstacle is detected in the pathway, then also the SMS and buzzer is used to inform the operator. The AGV reaches the destination and goods get unloaded.

\section{ADVANTAGES}

[ Performance and efficiency is very high

[ Errors are almost zero

[ Less skilled operator is required

[ Low cost

\section{DISADVANTAGES}

The only disadvantage of this system is that the navigation of the AGV can be controlled within a limited range.

\section{CONCLUSIONS}

The AGV takes the goods from one service station to another service station without the help of humans. Obstacle detection and overload detection is done with the help of sensors to the operator. The RFID technology has many advantages which helps in the navigation of AGV and the GSM system in giving alerts to the operator.

\section{REFERENCES}

[1] An RFID based pilgrim identification systemMohammed Mohandes, MaanKousa, Ahmed A Hussain

[2] Control and path prediction of an Automated guided vehicle-S.Butdee, A.Suebsomran, F.Vignat, P.K.D.V.Yarlagadda.

[3] Estimation and control of an automated guided vehicleSuthepButdee, Frederic Vignat, Anan Suebsomran, Prasad KDV Yarlagadda

[4] Designing and methodology of automated guided vehicle robots/ self guided vehicles systems, future trends- SajjadYaghoubi, SanamKhalilis, Reza Mohammad Nezad.

[5] Design and development of a control unit of an automated guided vehicle-M.R.S.Rupasri, Y.Shivraj Narayan, Abhilash. 